\title{
Emergency Contraceptive Pills as a Backup for Lactation Amenorrhea Method of Contraception and the Plan of Nursing Action.
}

\author{
Manar Fathy Heeba ${ }^{1}$ \\ ${ }^{I}$ (Lecturer of Maternal, Obstetrical and Gynecological nursing, Port Said University)
}

\begin{abstract}
Background: Lactation amenorrhea provides natural protection against pregnancy for up to six months after birth, however, it should backed up by emergency contraceptive pills until the transition to other family planning methods during the postpartum period to prevent the adverse effect of unintended pregnancy.

Aim: assess the factors influencing LAM and evaluate the effectiveness of an educational program on nurse's knowledge toward using ECPs as a backup for lactation amenorrhea.

Subjects and methods: cross sectional descriptive survey for women and a quasi-experimental intervention study for nurses were used in this study. A random sample of 614 women was recruited from women attending pediatric clinics for immunization of their children at fourteen primary health care centers in Port-Said and 27 maternity nurses were selected purposively for the intervention part of this study. The researcher used two main tools a structured interview questionnaire for women and self-administrated questionnaire for the nurses. The results revealed that $73.9 \%$ of the women used lactation amenorrhea method less than 6 months and $26.1 \%$ used it from 6-24 months. The majority (99.5\%) did not know the criteria of lactation amenorrhea and $80.8 \%$ of them had resumed their menstruation before 6 months. Regularity of menstruation, the return of menstruation and the use of contraception had the most positive factors effect on LAM, Differences observed are statistically significant ( $p=0.05, p=0.012, p=0.0001$ respectively). Almost one fifth $(17.3 \%)$ were exposed to unintended pregnancy, $86.8 \%$ saved pregnancy until labor. The vast majority (97.6\%) of women had lack of knowledge about emergency contraceptive pills. The implementation of nursing educational program was associated with statistically significant improvement in nurse's knowledge of lactation amenorrhea method and emergency contraceptive pills.

Conclusion: lactation amenorrhea method was used up to six months by almost three quarters of the sample but the great majority lack knowledge about the criteria of lactation amenorrhea method and emergency contraceptive pills that is why almost one fifth were exposed to unintended pregnancy. Significant improvement of nurse's knowledge was shown after the implementation of the educational program.

Recommendations: maternity nurses should increase women's awareness and knowledge about the criteria of LAM and the importance of using ECPs to support LAM in case of unprotected intercourse and until more effective contraceptive method is used.
\end{abstract}

Keywords: Lactation amenorrhea method, Emergency contraception, unplanned pregnancy, Maternity Nurses .

\section{Introduction}

In last decades Egypt had suffered major socioeconomic consequences of overpopulation problem, which resulted from high level of birth rate. Over population and unplanned population growth impede the socioeconomic development, hinder prosperity, and threatens the health status of community members ${ }^{[1]}$.

Attempts to provide fertility awareness-based method of family planning to breastfeeding women led to the development of lactation amenorrhea method (LAM) of postpartum contraception, which is the practice of using breastfeeding to prevent pregnancy. There is a growing amount of evidence that, when used perfectly i.e has three elements: (a) full or nearly full breastfeeding; (b) postpartum amenorrhea; and (c) an infant aged less than six months provide 98 to $99 \%$ contraceptive effectiveness ${ }^{[2]}$.

Unintended pregnancy is a global problem ${ }^{[3]}$. Nearly 4 in 10 pregnancies around the globe are unplanned and about 2 in 10 ends in abortion ${ }^{[4]}$. Such pregnancies, in addition to their negative social impact, may lead some women to seek induced abortion, a procedure which, in settings (like Egypt) where abortion is illegal, is often unsafe ${ }^{[5]}$.

The lack use of contraceptives and the lack of knowledge about the proper use of contraceptives are the major reasons for unintended pregnancy. Emergency contraceptive (EC) reduce the need for induced abortion and related complexities. Knowledge of EC would protect a large number of women's from trauma of induced abortions, as well as reduce morbidities and mortalities and pregnancy complications ${ }^{[6]}$. The expiration of LAM requirements can occur unexpectedly at a time when the woman is not ready to visit a clinic to initiate 
another contraceptive. Moreover, many Egyptian women are unaware of the appropriate criteria of utilizing LAM which may lead to unplanned or sometimes unwanted pregnancy. Therefore the presence of a safe method that can help these women to avoid unplanned pregnancy can increase their trust of LAM as an effective method of contraception ${ }^{[7]}$

\section{I.1 Aim of the Study}

To assess the factors influencing LAM and evaluate the effectiveness of an educational program on nurse's knowledge toward using ECPs as a backup for lactation amenorrhea

I.1 .1 Specific objectives:

The aim was achieved through:-

1. Finding out the factors influencing LAM

2. Estimation of the incidence of unwanted pregnancy, causes and consequences of unwanted pregnancy

3. Assessment of women awareness towards the use of ECPs as a last chance to prevent unwanted pregnancy

4. Evaluation of the effectiveness of an educational program on nurses knowledge toward ECPs to support LAM of contraception

\section{I.1 .2 Research hypotheses:-}

The level of nurse's knowledge will be improved after attending the educational program.

\section{a) Technical design}

\section{Methodology}

II.1 Research design: two research designs were used in this study: cross sectional descriptive survey and a quasi-experimental intervention study.

II. 2 Study setting: the present study was carried out in fourteen primary health care centers representing the six districts of Port-said, namely: Port-fouad first, Port-fouad second, El Kuwait, Fatma elzahraa, El abouty, Mostafa kamel, El arab child care, Bank elescan, El manakh first, El arab first, Omar Ebn Elkhatab, Osman Ebn Afan, and El gawhara and El manakh child care.

II.3 Subjects: II.3.1 A purposive sample of lactating women (from the previous mentioned settings) who attended either for family planning or child immunization services during the study period "seven months" were included in the study according to the following criteria: Lactating women who used lactational amenorrhea as method of contraception for at least 6 months and more, delivered a viable healthy newborn and willing to participate in the study.

II.3.2 All nurses working in the previous mentioned settings, who are willing to participate in the program, were recruited for this study.

II.4 Tools for data collection:

Two main tools were used for data collection:

\section{II.4 .1 A structured interview questionnaire for the women:}

This questionnaire sheet was developed based on current related literature, it covered the following parts:- personal data, menstrual history, obstetrical history, medical history, family income, use of LAM as a method of contraception and women knowledge and practice about the use of ECPs as a backup of LAM "in case of unprotected intercourse" and whether she used any other method of contraception after the resumption of menstruation ${ }^{[8]}$.

Scoring: For the knowledge items, a correct response was scored 1 and the incorrect zero. The items were summed up and the total divided by the number of the items, giving a mean score for the part. These scores were converted into a percent score, means and standard deviations were computed. Knowledge will consider satisfactory if the percent score $60 \%$ or more and unsatisfactory if less than $60 \%$.

II.4 .2 Self-administrated questionnaires for the nurse: This questionnaire sheet was developed based on current related literature ${ }^{[6,7]}$. It includes: -, II.4.2.1: Knowledge questionnaire to assess nurse's knowledge as regard: Lactation amenorrhea as a method for contraception and Emergency contraceptive pills.II.4.2.2 Program booklet: A booklet included information about Lactation amenorrhea as a method of contraception (time of using, efficacy, criteria and mode of use). It also entails information about the importance of ECPs to support LAM. The types, mode of action, indication, efficacy, and time of use, mode of use, side effect and contraindication were all included.

Scoring: For the knowledge items, a correct response was scored 1 and the incorrect zero. The items were summed up and the total divided by the number of the items, giving a mean score for the part. These scores were converted into a percent score, means and standard deviations were computed. Knowledge was considered satisfactory if the percent score $60 \%$ or more and unsatisfactory if less than $60 \%$.

\section{B) Administrative design:-}


An official letter from the dean of the faculty of nursing was sent to the director of the selected area of the study.

\section{C) Operational design:-}

Field of work this was carried out through the following phases

Preparation phase:

The preparatory phase aimed to complete the preparation of the tools and the educational program. The tools were reviewed by a jury of 10 experts in the field of obstetrics and gynecological nursing.

A pilot study was carried out over a period of two months. It was conducted on $10 \%$ of total sample size involving women and nurses to evaluate the content validity, time required to fill each tool and feasibility of tools of the study. Necessary modifications were carried out as revealed from the pilot study. The field work lasted 7 months from the beginning of March 2016 to the end of September 2016. The data were collected according to the following phases:

\section{Assessment phase:}

The researcher interviewed women to assess women knowledge and practice regarding, LAM, time of resumption of menstruation, the occurrence of unintended pregnancy also, using ECPs. The assessment with each woman took about one hour. A pretest self-administered questionnaire was used to assess nurse's knowledge about LAM and ECPs. This was also used for the posttest. The assessment with each nurse took about one hour.

\section{Implementation phase of the program:}

The researcher started to implement the program sessions for the intervention group. The researcher was available six days / week in the study settings alternatively.The total number of sessions was nine sessions for theoretical knowledge, each session took about one hour. The attended number of nurses in each session were between two to three nurses.

\section{Evaluation phase:}

After the completion of the program, the post-test was done immediately after the program using the pre/post-test questionnaire to assess the nurse knowledge. A follow up evaluation was also done after three months to find out the retention of the information given.

\section{Ethical consideration}

The researcher explained the aim of the study to each nurse and woman to have their oral consent. This was obtained after a brief explanation of the study to assure them that the information obtained were confidential and used only for the purpose of the study.

As for the limitation of the study; it was difficult to gather all the nurses together at the same time to attend the sessions of the program due to their working circumstances. This was considered and arranged during the implementation of the study. Moreover, the researcher faced with hard effort to select the purposive sample of women with the previously inclusion criteria.

\section{D) Statistical design:-}

Data entry and statistical analysis were done using SPSS 16.0 statistical software package. Data were presented using descriptive statistics in the form of frequencies and percentages for qualitative variables, and means and standard deviations for quantitative variables. Categorical variables were compared using chi-square test. Whenever the expected values in one or more of the cells in a $2 \times 2$ tables was less than 5 , Fisher exact test was used instead. In larger than $2 \times 2$ cross-tables, no test could be applied whenever the expected value in $10 \%$ or more of the cells was less than 5. Pearson correlation analysis was used for assessment of the interrelationships among quantitative variables, and Spearman rank correlation for ranked ones. To assess the relationship between scores of knowledge and attitude as dependent factors, on the one hand, and various quantitative factors, as independent factors, on the other hand, multiple stepwise backward regression analysis was used, and analysis of variance for the full regression models were done. Statistical significance was considered at $\mathrm{p}$-value $<0.05$.

\section{Results}

Table 1 revealed that women age ranged between 17-42 years with a mean age of $28.1 \pm 4.8$ years with the highest percentage $(38.4 \%)$ was less than 25 years of age. More than half $(52.6 \%)$ of the women had secondary level of education, while $22.0 \%$ had university level of education. The majority was house wives $(88.9 \%)$.

Table 2 revealed that, almost three fourth (73.9\%) of the studied women used LAM for a period less than 6 months and $20.7 \%$ use it up to 12 months after delivery. The great majority $(99.5 \%)$ did know the criteria of LAM and $80.8 \%$ had resumed their menstruation before 6 months. While, less than one fifth $(17.1 \%)$ had resumed their menstruation between 6-12 months and only $2.1 \%$ had resumed it after 12 month. 
Table 3 shows the factors affecting the use of LAM for more than the first 6 months after delivery. As indicated from the table regularity of menstruation, the return of menstruation and the use of contraception had the most positive effect on LAM. Differences observed are statistically significant $(\mathrm{p}=0.05, \mathrm{p}=0.012, \mathrm{p}=0.0001$ respectively).

Table 4 show that nearly one fifth of the women (17.3\%) were exposed to unintended pregnancy. The most common cause was irregularity in taking contraceptive pills $(39.6 \%)$, followed by $28.3 \%$ who refused to take any method or $22.6 \%$ who relied on LAM. Meanwhile, less than one fifth suffered from unintended pregnancy due to the failure of the method used $(7.6 \%$ and $1.9 \%)$ and most of them $(86.8 \%)$ saved their pregnancy until the labor but $13.2 \%$ resorted to induced abortion.

Table 5 demonstrates that, the great majority of women (97.6\%) were not aware about the ECPs and only $0.7 \%$ of them who had correct knowledge about the time of using ECPs. The main source of their information was neighbors/friends, followed by physicians and nurses (33.3\%, 20.0\%, and 13.3\% respectively). All women did not depend on ECPs as a backup for LAM because they never heard about it, thought that they were not in need for it or being afraid from its complications $(97.6 \%, 2.0 \%$ and $0.5 \%$ respectively).

Table 6 shows that statistically significant improvement was revealed at both the post and follow-up phases in all area of tested knowledge $(\mathrm{p}<0.001)$ except the knowledge about effectiveness, criteria, definition and types of LAM. At the follow-up, only knowledge about the criteria and types of LAM did not decline. Although, all the other areas have demonstrated some decline but still were statistically significant higher than the pre-program levels.

Figure 1 points to statistically significant improvement that was revealed at both the post and followup phases. Despite the fact that $11.1 \%$ of nurses had unsatisfactory knowledge at the follow up, the level at the follow-up phase was still statistically significant higher than the pre- program levels.

Table 1 Distribution of the Studied Women According to their Socio-Demographic Characteristics.

\begin{tabular}{|l|c|c|}
\hline \multirow{2}{*}{ Socio-demographic characteristics } & \multicolumn{2}{|l|}{ Studied women $(\mathbf{n}=\mathbf{6 1 4})$} \\
\cline { 2 - 3 } & No. & $\mathbf{\%}$ \\
\hline Age (years) & 236 & 38.4 \\
\hline $17-25$ & 178 & 29.0 \\
\hline$>25-35$ & 200 & 32.6 \\
\hline$>35-42$ & \multicolumn{2}{|c|}{$\mathbf{1 7 . 0 - 4 2 . 0}$} \\
\hline Min-Max & \multicolumn{2}{|c|}{$\mathbf{2 8 . 1} \pm \mathbf{4 . 8}$} \\
\hline Mean \pm SD & \multicolumn{2}{|c|}{} \\
\hline Level of education & 41 & 6.6 \\
\hline Illiterate & 33 & 5.4 \\
\hline Reading \& write & 4 & 0.7 \\
\hline Basic & 33 & 5.4 \\
\hline Preparatory & 323 & 52.6 \\
\hline Secondary education & 45 & 7.3 \\
\hline Technical health institute & 135 & 22.0 \\
\hline University & & \\
\hline Job & 546 & 88.9 \\
\hline House wives & 68 & 11.1 \\
\hline Working & &
\end{tabular}

Table 2 Distribution of the Studied Women According to use the criteria of Lactational Amenorrhea.

\begin{tabular}{|l|c|c|}
\hline \multirow{2}{*}{ Criteria of Lactational amenorrhea } & \multicolumn{2}{|l|}{ Studied women $(\mathbf{n = 6 1 4})$} \\
\cline { 2 - 3 } & No. & \% \\
\hline Duration of use (months) & & \\
\hline$<6$ & 454 & 73.9 \\
\hline $6-12$ & 127 & 20.7 \\
\hline$>12$ & 33 & 5.4 \\
\hline Use the criteria of Lactational amenorrhea & & \\
\hline Yes & 3 & 0.5 \\
\hline No & 611 & 99.5 \\
\hline Time of resumption of menstruation (months) & & \\
\hline$<6$ & 496 & 80.8 \\
\hline $6-12$ & 105 & 17.1 \\
\hline
\end{tabular}




$$
\begin{array}{|l|l|l|}
\hline>12 & 13 & 2.1 \\
\hline
\end{array}
$$

Table 3 Binary Regression Model among the Studied Women for the Factors Affecting the Use of LAM after the 6 Months

\begin{tabular}{|l|c|c|c|c|}
\hline Variables & $\mathbf{B}=\mathbf{6 1 4} \mathbf{.}$ & S.E. & Wald & P-value \\
\hline Positive factors & & & & \\
\hline Family income & 0.4 & 0.4 & 0.9 & 0.351 \\
\hline Regularity of menstruation & 0.9 & 0.4 & 3.9 & $\mathbf{0 . 0 5}$ \\
\hline Number of gravidity & 0.5 & 0.4 & 1.6 & 0.207 \\
\hline Number of parity & 0.1 & 0.4 & 0.1 & 0.749 \\
\hline Use of contraception & 4.0 & 0.3 & 151.9 & $<\mathbf{0 . 0 0 0 1}^{*}$ \\
\hline Return of menstruation & 0.9 & 0.4 & 6.4 & $\mathbf{0 . 0 1 2}^{*}$ \\
\hline Negative factors & & & & \\
\hline Suffering from chronic diseases & -0.4 & 0.4 & 1.3 & 0.253 \\
\hline Number of feeding & -0.3 & 0.4 & 0.5 & 0.502 \\
\hline Awareness of ECPs & -0.2 & 0.7 & 0.1 & 0.819 \\
\hline Time of start weaning & 0.0 & 0.4 & 0.0 & 0.935 \\
\hline Constant & $\mathbf{- 6 . 6}$ & $\mathbf{1 . 8}$ & $\mathbf{1 3 . 3}$ & $<\mathbf{0 . 0 0 0 1}$ \\
\hline
\end{tabular}

Table 4 Distribution of the Studied Women According to their Current Unintended Pregnancy [n=614].

\begin{tabular}{|l|c|c|}
\hline \multirow{2}{*}{ Unintended pregnancy } & \multicolumn{2}{|c|}{$\begin{array}{c}\text { Studied women } \\
\text { (n=614) }\end{array}$} \\
\cline { 2 - 3 } & No. & \% \\
\hline Occurrence of unintended pregnancy & & \\
\hline Yes & 106 & 17.3 \\
\hline No & 508 & 82.7 \\
\hline Causes of unintended pregnancy [n=106] & & \\
\hline Reliance on breast feeding & 24 & 22.6 \\
\hline Irregular intake of contraceptive pills & 42 & 39.6 \\
\hline Did not take any contraceptive methods & 30 & 28.3 \\
\hline The occurrence of pregnancy while using the intrauterine device & 8 & 7.6 \\
\hline Tear of condom & 2 & 1.9 \\
\hline Consequence of unintended pregnancy [n=106] & & \\
\hline Saving pregnancy until the labor & 92 & 86.8 \\
\hline Induced abortion & 14 & 13.2 \\
\hline
\end{tabular}

Table5 Distribution of the Studied Women According to their Awareness about Emergency contraceptive pills [n=614].

\begin{tabular}{|l|c|c|}
\hline \multirow{2}{*}{ Awareness about emergency contraceptive pills } & \multicolumn{2}{|c|}{$\begin{array}{c}\text { Studied women } \\
\text { (n=614) }\end{array}$} \\
\cline { 2 - 3 } & No. & \% \\
\hline Aware about emergency contraceptive pills & & 97.6 \\
\hline No & 599 & 2.4 \\
\hline Yes & 15 & \\
\hline Timing of using emergency contraceptive pills [n=15] & & 0.7 \\
\hline After the intercourse & 4 & 0.8 \\
\hline Before the intercourse & 5 & 0.0 \\
\hline During the intercourse & 0 & 1.0 \\
\hline During the feeling of any signs and symptoms of pregnancy & 6 & \\
\hline Sources of information [n=15] & & 20.0 \\
\hline Physicians & 3 & 13.3 \\
\hline Nurses & 2 & 6.7 \\
\hline Pharmacist & 1 & 33.3 \\
\hline Neighbors/friends & 5 & 6.7 \\
\hline Media & 1 & 20.0 \\
\hline Readings & 3 & \\
\hline Reliance on emergency contraceptive pills & & \\
\hline Yes & 0 & 0.0 \\
\hline No & 0 & 0.0 \\
\hline Not known & 614 & 100.0 \\
\hline Used emergency contraceptive pills & & \\
\hline Yes & 0 & 0.0 \\
\hline No & 614 & 100.0 \\
\hline Reasons for not using emergency contraceptive pills & & \\
\hline Did not hear about it & 599 & 97.6 \\
\hline Have no need for it & 12 & 2.0 \\
\hline Being afraid from its complications & 3 & 0.5 \\
\hline
\end{tabular}


Table 6 Distribution of Nurses According to Satisfactory Knowledge about Emergency Contraceptive Pills throughout the Program Phases

\begin{tabular}{|c|c|c|c|c|c|c|c|c|}
\hline \multirow[t]{3}{*}{ Areas of knowledge } & \multicolumn{6}{|c|}{$\begin{array}{l}\text { Satisfactory knowledge of nurses } \\
(n=27)\end{array}$} & \multirow[t]{3}{*}{ P-value 1} & \multirow[t]{3}{*}{ P-value 2} \\
\hline & \multicolumn{2}{|c|}{ Before } & \multicolumn{2}{|c|}{ After } & \multicolumn{2}{|c|}{ Follow up } & & \\
\hline & No. & $\%$ & No. & $\%$ & No. & $\%$ & & \\
\hline $\begin{array}{l}\text { Effectiveness of } \\
\text { lactation } \\
\text { amenorrhea method }\end{array}$ & 17 & 63.0 & 24 & 88.9 & 23 & 85.2 & 0.039* & 0.07 \\
\hline $\begin{array}{l}\text { Criteria of lactation } \\
\text { amenorrhea method }\end{array}$ & 22 & 81.5 & 26 & 96.3 & 26 & 96.3 & 0.125 & 0.219 \\
\hline $\begin{array}{ll}\text { Definition } & \text { of } \\
\text { emergency } & \\
\text { contraceptive pills } & \\
\end{array}$ & 26 & 96.3 & 26 & 96.3 & 25 & 92.6 & $\mathbf{1 . 0}$ & 1.0 \\
\hline $\begin{array}{l}\text { Components of } \\
\text { emergency } \\
\text { contraceptive pills }\end{array}$ & 3 & 11.1 & 21 & 77.8 & 14 & 51.9 & $<0.0001 *$ & $0.007 *$ \\
\hline $\begin{array}{l}\text { Types of emergency } \\
\text { contraceptive pills }\end{array}$ & 24 & 88.9 & 27 & 100.0 & 27 & 100.0 & 0.25 & 0.25 \\
\hline $\begin{array}{l}\text { Mode of action of } \\
\text { emergency } \\
\text { contraceptive pills }\end{array}$ & 4 & 14.8 & 24 & 88.9 & 17 & 63.0 & $<0.0001 *$ & $<0.0001 *$ \\
\hline $\begin{array}{ll}\text { Indications of } \\
\text { emergency } \\
\text { contraceptive pills }\end{array}$ & 8 & 29.6 & 26 & 96.3 & 23 & 85.2 & $<0.0001 *$ & $<0.0001 *$ \\
\hline $\begin{array}{l}\text { Time of emergency } \\
\text { contraceptive pills }\end{array}$ & 10 & 37.0 & 24 & 88.9 & 23 & 85.2 & $<0.0001 *$ & $<0.0001 *$ \\
\hline $\begin{array}{l}\text { Mode of use of } \\
\text { emergency } \\
\text { contraceptive pills }\end{array}$ & 0 & 0.0 & 23 & 85.2 & 18 & 66.7 & $<0.0001 *$ & $<0.0001 *$ \\
\hline $\begin{array}{l}\text { Effect of emergency } \\
\text { contraceptive pills }\end{array}$ & 4 & 14.8 & 26 & 96.3 & 19 & 70.4 & $<0.0001 *$ & 0.001* \\
\hline $\begin{array}{l}\text { Side effects of } \\
\text { emergency } \\
\text { contraceptive pills }\end{array}$ & 6 & 22.2 & 25 & 92.6 & 15 & 55.6 & $<0.0001 *$ & $0.022 *$ \\
\hline $\begin{array}{l}\text { Contraindications of } \\
\text { emergency } \\
\text { contraceptive pills }\end{array}$ & 10 & 37.0 & 24 & 88.9 & 21 & 77.8 & 0.001* & 0.001* \\
\hline
\end{tabular}

P-value 1: for Mac Nemar test for Significance between before/after.

P-value 2: for Mac Nemar test for Significance between before/follow up cant at $\mathbf{P} \square \mathbf{0 . 0 5}$

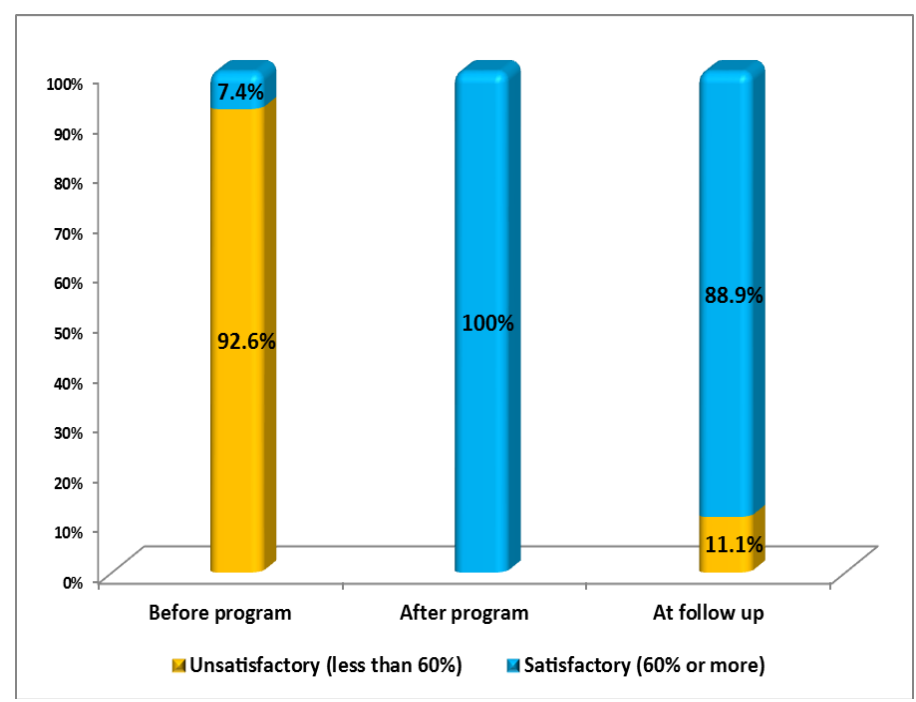

Figure 1 Nurses' total Knowledge about Emergency Contraceptive Pills throughout the Program phases $(\mathbf{n}=27)$. 


\section{Discussion}

Although, family planning and reproductive health programs have contributed immensely to a global decline in the incidence of unintended pregnancy; however, the rates are still very high in some developing countries including Egypt $^{[8]}$.

In the present study, almost one tenth of studied women had resumed their menstruation after the six months after delivery and had exclusively breast feeding their children up to six months of age. Such results are in agreement with Dulli, (2013) study titled the Formative Research to Improve the Promotion of the Lactational Amenorrhea Method (LAM) and Exclusive Breastfeeding (EBF) in the MAHEFA USAID/Madagascar Program, Ambilobe District, DIANA Region ${ }^{[9]}$. They reported that LAM use in Madagascar was 8.1 percent among women less than 6 months postpartum. Between 6 and 12 months postpartum, modern FP use was very low at 18.1 percent. Exclusive breast feeding, a prerequisite for LAM use, is also low in Madagascar during the first 6 months after delivery, with only 29.8 percent of women reporting exclusively breastfeeding their infant through 5 months postpartum ${ }^{[10]}$. Similarly, Black et al., (2013) found that practicing EBF in the first 6 months of life and continued breastfeeding from 6 to 11 months was identified as one of the single most effective preventive interventions in reducing child mortality by the Bellagio Child Survival Study Group (2003), with the potential of saving 1.3 million lives annually. Moreover, sub-optimal breastfeeding is responsible for 11.6 percent of the deaths of children under 5 worldwide ${ }^{[11]}$.

In this study, there are some factors which have positive influence on LAM. These include; regularity of the menstruation, numbers of gravidity and parity, use of contraception and family income. On the other hand those who had negative influence on LAM were; the occurrence of chronic diseases, number of feeding, awareness of ECPs and the onset of weaning. These results are supported by Ekpenyong et al., (2013) who were found that knowledge and practice among LAM users was positively influenced by education level, parity, marital status and age of users. Poor knowledge of the method, and incorrect practices by LAM users can negatively influence on the practice of LAM and responsible for the high failure rate recorded in prior studies $[12]$.

Pinto, (2005) \& Radwan et al., (2009) also reported that, the duration of breastfeeding seems to be the most significant variable in explaining the resumption of menses among urban Bolivian women. However, concerning the relationship between breastfeeding and amenorrhea it depends on other factors such as parity, use of contraception, and especially women education also play an important role in the return of menstruation. It is well documented that women who receive prenatal care and attend prenatal educational classes are more likely to have breastfeeding duration levels closer to the recommendation by the WHO than women who do not receive prenatal care ${ }^{[13,14]}$.

The World Health Organization (WHO) estimates that worldwide 210 million women become pregnant each year and that about one-third of pregnancies end in miscarriage, stillbirth, or induced abortion ${ }^{[15]}$. In Ireland the term "crisis pregnancy" refers to pregnancies that are unintended and unplanned and that represent a personal trauma for the woman or couple involved ${ }^{[16]}$. Unintended pregnancies in the Middle East and North Africa countries (MENA) were estimated between $15 \%$ and 58\%, either mistimed when occur or unwanted at all ${ }^{[17]}$.

This is supported by the finding of the present study, where almost one fifth of women were exposed to unintended pregnancy, because of carelessness or forgetfulness of taking the contraceptive pills, avoiding taking any contraceptive methods, their reliance on breastfeeding or the failure of the method used. Similar findings have been reported that the incidence of unintended pregnancy among lactating mothers practicing LAM was $14.3 \%$. This value is relatively lower than values obtained in previous studies within and outside Nigeria ${ }^{[12]}$. Omar and Anna (2008) reported in Turkey; the incidence was recorded as $32.8 \%$. In the researcher point of view could probably be due to variations in some socio-demographic variables among the different populations under study ${ }^{[18]}$. In the present study, most of the participants were highly educated, married, multiparous and between the ages of 31 and 35 years. These attributes have been consistently shown in previous surveys to improve knowledge and practice of LAM among users.

Regarding to the consequences of unintended pregnancy, most of the studied women in the current study kept the pregnancy until delivery, while, more than one-tenth of them were exposed to induced abortion.

Emergency contraceptive pills (ECPs) is a method of contraception used after intercourse and before the potential time of implantation, offers women a last chance to prevent pregnancy after unprotected intercourse ${ }^{[19]}$. Since it is difficult to determine the infertile time of the cycle with certainty emergency contraceptive better be provided for any women who is concerned about her risk of pregnancy, regardless of the cycle day of exposure ${ }^{[20]}$. Effectiveness of ECPs said to be $75 \%$ to $85 \%{ }^{[21]}$. 
The present study shows that minority of women were aware about the ECPs. While the great majority had no idea about them. This is in agreement with Marafie et al., (2007) who reported that awareness of women in Arab world regarding ECPs was very low ${ }^{[22]}$. Conversely, Agrawal \& Agrawal, (2013) and Tesfa et al., (2015) found that $40.5 \%$ of the total respondents had heard about EC, of those $77.4 \%$ ever heard of EC mentioned ECPs. The majority of them 238 (83.8\%) were between the age of 14-17 years and were married $[21,23]$.

The difference between the above mentioned studies and the present one might be attributed to differences in the community culture, and traditions. Thus, in a country like Sweden, where ECPs is available over the counter, it was found that almost all Swedish women $(90.0 \%)$ in the study sample were familiar with ECPs. Hence unawareness about the proper method of using this pill can not only lead to unwanted pregnancy but also may create health hazard ${ }^{[24]}$.

Regarding the main source of information about ECPs, neighbors/friends, followed by physicians were constituting the most common source of information. However, all the women did not depend on ECPs as a backup for LAM in case of unprotected intercourse, because nobody told them about their importance in this issue. This is matching with other investagoters ${ }^{[22,25]}$. However, in contradiction with the above mentioned result, researchers have reported that the most common source of information about ECPs was the mass media $(35.6 \%)$ followed by health professions $(17.4 \%)$, school and $(15.7 \%)$ friends. The possible reason may be due to the fact that mass media is more accessible to the women together with the fact that there is special attention from the central level about this issue ${ }^{[21,23]}$.

Post-coital contraception is a sensitive issue to raise in conservative communities, like Egypt especially when there are many cultural and religious restraints, very low awareness about emergency contraception (EC) among healthcare professionals and eligible clients, as well as widespread misconceptions that may have an immense negative impact on such an issue ${ }^{[26]}$.

The current study finding has shown that despite the fact that all nurses were aware about ECPs; their baseline knowledge about it was very low. Thus, at the pre-planning phase of the educational program, none of the nurses had a satisfactory knowledge about the component of the EC pills, mode of action, indication, time, mode of use, effect, side effect as well as contraindication. These finding are in agreement with the researcher who have similarly documented poor knowledge among nurses about ECPs ${ }^{[27]}$. This might be attributed to the fact that ECPs is a relatively new method, less commonly advised by the physicians, and there is less stress about it in nursing curriculum and ongoing training. Moreover, Egyptian mass media do not provide enough propaganda about it.

The result of the present study has shown that the training program developed and implemented for nurses was successful in improving their knowledge regarding ECPs. Hence, at the post-test, all the study nurses had satisfactory knowledge. However, some decline was revealed at the three months follow-up, which was most obvious in knowledge. Nonetheless, the level at the follow-up was still significantly higher, compared to the pre-program levels. Thus there is a need for booster session for the nurses to retain the acquired gains from the program. These finding are agreed with the study conducted by Sharawy, (2014) almost has the same results ${ }^{[27]}$.

\section{Recommendations}

In the light of the main study finding, the following recommendations are proposed.

- Family planning counseling by the nurse midwife including LAM must be emphasized as an integral part of any family planning activities and programs.

- There is a great need to increase women's awareness and knowledge about the criteria of LAM and the importance of using ECPs to support LAM in case of unprotected intercourse.

- Continuous refreshing courses about ECPs for nurses including the newly appointed nurses as well as regular supervision and evaluation of nurse's performance. This is essential to upgrade their knowledge and practice concerning all contraceptive methods.

- Mass media could help in enlightening women about the criteria of LAM, the ECPs and the importance of using effective method when LAM is expired.

\section{Conclusion}

In the light of the present study finding, it can be concluded that: Regularity of menstruation, the return of menstruation and the use of contraception had the most positive factors effect on LAM. LAM was used up to six months by almost three quarters of the sample but the great majority lack knowledge about the criteria of LAM and ECPs that is why almost one fifth were exposed to unintended pregnancy. Significant improvement of nurse's knowledge was shown after the implementation of an educational program. 


\section{References}

[1]. Basavanthappa B.T. (2008): Community Health Nursing.2nd edition. Jaypee Publishers. NewDelhi: pp. $561-562$.

[2]. Afifi M.M. (2007): Lactational Amenorrhoea Method For Family Planning And Women Empowerment In Egypt, Singapore Med $J, 48$ (8): 758-762.

[3]. Fathalla M.F., Abdel-Raheem M.S., Amin A. (2003): The prevalence, determinants and outcome of unintended pregnancy: a hospital-based study. Egypt Soc Obstet Gynecol; 29:945-54.

[4]. Trussell J., Wynn L.L. (2008): Reducing unintended pregnancy in the United States. Contraception; 77: pp.1-5.

[5]. Shah I., Ahman E. (2009): Unsafe abortion: global and regional incidence, trends, consequences, and challenges. J Obstet Gynaecol Can; 31: 1149-58.

[6]. The Alan Guttmacher Institute (AGI) (2014): Contraceptive Use in the United States, New York. Available at; https://www.guttmacher.org/fact-sheet/contraceptive-use-united-states. [Accessed October, 2014].

[7]. Shaaban O.M., Hassen S.G., Nour S.A., Kames M.A., Yones E.M. (2013): Emergency contraceptive pills as a backup for lactational amenorrhea method (LAM) of contraception: a randomized controlled trial, Elsevier Inc; 7929:1-7.

[8]. Singh S., Sedge G., Hussain R. (2010): Unintended pregnancy: worldwide levels, trends and outcomes. Studies in family planning, 41(4):pp. 241-250.

[9]. Dulli L (2013): Secondary analysis of data from the Madagascar Standard DHS, 2008-09. Antananarivo, Madagascar: MEASURE DHS, ICF International.

[10]. INSTAT, ICFMacro (2010): Enquête Démographique et de Santé de Madagascar 2008-2009. Calverton Maryland: Institut National de la Statistique.

[11]. Black R.E., Victora C.G., Walker S.P., et al. (2013): Maternal and child undernutrition and overweight in low-income and middleincome countries. Lancet; 382(9890): pp. 427-451.

[12]. Ekpenyong C. E., Daniel N. E., Uwah A. F., Ettebong E. O., Ibu J. O. (2013): Lactational amenorrhoea method of contraception: An in-depth study of awareness, knowledge and pregnancies.

[13]. Pinto G. (2005): Breastfeeding and Postpartum Amenorrhea among Bolivian Women: A Survival Analysis. Center for Demography and Ecology. University of Wisconsin-Madison, CDE Working Paper No. 2005-01; Available at: https://www.ssc.wisc.edu/cde/cdewp/2005-01.pdf.

[14]. Radwan H., Mussaiger A., Hachem F. (2009): Breastfeeding And Lactational Amenorrhea In The United Arab Emirates. Journal Of Bediatric Nursing, 24(1):62-68 \& 71-78.

[15]. World Health Organization (WHO) (2007): Unsafe Abortion: Global and Regional Estimates of the Incidence of Unsafe Abortion and Associated Mortality in 2003, 5th ed.

[16]. McBride O., Morgan K., McGee H. (2012): Irish Contraception and Crisis Pregnancy Study 2012 (ICCP), A Survey of the General Population, Crisis Pregnancy Programme Report No 24, Crisis Pregnancy Programme, accessed 18th Feb 2015 from http://www.crisispregnancy.ie/crisis-pregnancy-help/overview/

[17]. Fahimi F.R., Abdul Monem A. (2010): Unintended Pregnancies in the Middle East and North Africa. Population Reference Bureau. [cited 2013 May 11]. Available from: http://www.prb.org/Publications/PolicyBriefs/uninten dedpregnancies.aspx

[18]. Omar M.S., Anna F. (2008): Pregnancy during Breastfeeding In Rural Egypt. Contraception; 77(5): $350-354$.

[19]. Dray S. (2012): Unplanned pregnancy statistics. http://www.ehow.com/about 4611925 unplanned pregnancy statistics. html. accessed on March 10, 2012.

[20]. Mosher W.D., Jones J. (2012): Use of contraception in the United States: 1982-2008. National centre for health statistics. Vital health stat.23 (29). available at: http://www.cdc.gov/NCHS/datd/series/sr23/sr23-29.pdf.accessed 27 march 2012.

[21]. Agrawal V. K., Agrawal P. (2013): Knowledge, awareness and perception of female students of Emergency Contraceptive pills. Journal of Behavioral Health; 2(3): pp. 230-235.

[22]. Marafie N., Ball D.E., Abahussain E. (2007): Awareness of hormonal emergency contraception among married women in a Kuwaiti family social network. Eur J Obstet Gynecol Reprod Biol. 2007; 130: pp. 216-22.

[23]. Tesfa A., Bizuneh A.D., Tesfaye T., Gebru A.A., Ayene Y.Y., Birhan Alemnew Tamene B.A. (2015): Assessment of Knowledge, Attitude and Practice Towards Emergency Contraceptive Methods Among Female Students in Seto Semero High School, Jimma Town, South West Ethiopia. Science Journal of Public Health; 3(4): pp. 478-486.

[24]. Amalba A. , Mogre V., Appiah M. N, Mumuni W. A. (2014): Awareness, use and associated factors of emergency contraceptive pills among women of reproductive age (15-49 years) in Tamale, Ghana. . BMC Women's Health 2014; 14 (114): pp.1-6.

[25]. Sychareun V., Hansana V., Phengsavanh A., Phongsavan K. (2013): Awareness and attitudes towards emergency contraceptive pills among young people in the entertainment places, Vientiane City, Lao PDR. BMC Women's Health, 13:14.

[26]. Hanna S. (2013): Emergency contraceptive pills in Egypt: A challenging experience amidst a conservative culture. DKT International, Cairo, Egypt: pp. 259.

[27]. Sharawy H.R.M.R. (2014): Utilization Of Emergency Contraceptive Pills To Support Lactational Amenorrhea, Doctoral Thesis, Faculty Of Nursing, Zagazig university: pp.85- 98. 